\title{
Influence of Public Financial Management Reforms on Budget Implementation by Kenyan City Counties
}

\author{
Geofrey Abwao Magani, Joseph Mwangi Gichure \\ Department of Commerce and Economic Studies, Jomo Kenyatta University of Agriculture and Technology, Juja, Kenya
}

Email address:

maganigeofrey@gmail.com (G. A. Magani),gichure2009@yahoo.com (J. M. Gichure)

\section{To cite this article:}

Geofrey Abwao Magani, Joseph Mwangi Gichure. Influence of Public Financial Management Reforms on Budget Implementation by Kenyan City Counties. International Journal of Law and Society. Vol. 1, No. 2, 2018, pp. 46-63. doi: 10.11648/j.ijls.20180102.11

Received: October 29, 2017; Accepted: December 6, 2017; Published: January 15, 2018

\begin{abstract}
The pursuit of Public Financial Management Reforms (PFMR) is centered on, among other functions, enhancing transparency in governance, increasing prudential allocation of financial capital, accountability in financial management, separating policy and management functions. The PFMRs seek to address gaps identified in the devolved systems of government and public organizations to remedy inadequate strategy orientation and lapsed strategy as well as to build on institutional transformation. In Kenya, the PFMRs seek to ensure fiscal efficiency and discipline in the use of public finances by enhancing public service efficiency and safeguarding available resources to be used in the best interest of the people. This study sought to examine the influence public financial management reforms on budget implementation by Kenyan city counties. The PFMRs studies included IFMIS Re-Engineering and fiscal decentralization. The study was based on modern portfolio theory, resource-based theory and stakeholder theory and relied on an expost-facto descriptive research design with a survey method to determine the relationships between the study variables. Structured questionnaires, data collection sheets and interview schedules were used to collect data which was then cleaned, coded and scrutinized thoroughly for completeness. The study relied on primary data collected from the treasuries, directorates of economic planning, budget offices, IFMIS departments and sectoral departments of Nairobi city county, Mombasa city county and Kisumu city county respectively. Secondary data was obtained from the annual county governmets' budget implementation reports. The data was analyzed using SPSS version 24. Statistical measures such as means, percentages and standard deviation were used to interpret the data. The researcher also performed both a linear regression analysis and a Spearman correlation analysis to show the relationships between the study variables. The study revealed strong positive and statistically significant correlation between fiscal decentralization and budget implementation while IFMIS re-engineering had a negative and statistically insignificant correlation with budget execution. The results of the study were considered pivotal to the national government, the legislature, national treasury, county governments and respective sectoral departments, the Commission for Revenue Allocation, the office of the controller of budget, the public, budget implementation oversight agencies and county chiefs as it highlights important correlates of effective budget execution.
\end{abstract}

Keywords: IFMIS Re-Engineering, Fiscal Decentralization, Budget Implementation, Public Financial Management Reforms

\section{Introduction}

\subsection{Background to the Study}

Governments from all over the world have been implementing reforms affecting the public sector organizations. The reforms are widely promoted on grounds that the public sector is organized on wrong principles, inefficiencies, corruption and poor management of public funds thus the need for reinvention and institutional renewal.
The pursuit of reforms is centered on enhancing transparency, separation of policy and management functions, enhancing performance, and devolution of government activities [20]. The reforms are put in place to address gaps that have been identified, especially regarding the devolved systems of government, inadequate strategy orientation and lapsed strategy and to build on institutional transformation [43]. Drawing from the European Policy Brief of 2012, uncertainty of the European monetary union and failure to reverse the momentum of the European bond 
market uncertainties are noted despite numerous changes in economic governance [2]. This has been evidenced by the economic recession, souring unemployment, the mounting euro scepticism and the most recent Brexit. The reforms in Europe had policy priorities in boosting investment, supporting SMEs and entrepreneurship, boosting trade and bringing people back into work. In particular, the structural reforms emphasize on product market reforms, labour market reforms, tax structure reforms as well as public administration reforms to keep Euro afloat and the Euro area united, avoid competitive devaluations and protectionist national responses. However, a disintegration of the European Monetary Union (EMU), infamously referred to as Brexit, occurred despite the significant reforms to strengthen the EMU governance [19].

In Australia, quite a number of government policy changes have influenced the structure and operations of the Australian economy. The policies have been executed to induce higher levels of productivity to support higher living standards [7] $\&$ [37] to improve the efficiency of the operations as well as the distribution of resources of the economy [7]. Some of the reforms include deregulation of access to finance, floating the currency, significant decline in barriers to trade and Foreigh Direct Investment (FDI), commercialization of government business entities, strengthening competition and changing the institutional arrangement to reign in budget deficits and to empower the central bank to adjust the monetary policy. Singapore is considered one of the world's known beneficiaries of reforms and high national development, thanks to highly competent and least corrupted public administration. From the onset, the leadership of Singapore focused on reforming the public sector towards achieving a level of efficiency comparable to the Scandinavian countries, Germany, France and Switzerland among other wealthy western countries. The high level economic performance of Singapore draws from the country's commitment to reforms occasioned by effective governance founded on the principles of the rule of law; dynamic, forward-looking public service leadership; customer-centric as well as consultative government; incorruptible systems and efficient use of financial resources driven by the desire for a robust social security, sustainable economic growth, societal cohesiveness and cogenial international business supported by strong national identity and resilience [16].

\subsubsection{Public Financial Management Reforms}

The necessity of money in the public sector may be obvious, but in many parts of the world, good public financial management is often taken for granted. Public Financial Management (PFM) faces a number of issues including; rampant corruption, poor management of public resources, wrong prioritization of projects and initiatives as well as administrative and managerial inefficiencies [24]. As a result, governments are encouraged to apply best practices in undertaking various strategic Public Financial Management Reforms (PFMRs) for addressing their varied national development agenda [9]. The PFMRs are developments and changes in the field of finance that are sought to enhance transparency in governance, increase prudential allocation of resources, accountability in financial management, separate policy and management functions, to address inefficiencies, corruption and poor management of public funds. The adoption of PFMRs makes it possible to reorganize financially troubled organizations, enhance economic performance and devolution of government activities [20]. According to [32] the reforms are undertaken to deal with fiscal crises, public pressure, donor pressure, political crises and demands for regional affiliations to improve economic performance, public service delivery, and better living standards. In addition, the reforms are pursued to address gaps identified in the devolved systems of government and public organizations to remedy inadequate strategy orientation and lapsed strategy as well as to build on institutional transformation [43]. Various countries have undertaken different approaches to enhance the adoption of the PFMRs. In Liberia, the new Ministry of Finance and Development Planning works around public sector financial management reform to address severe economic decline during the civil crisis, a period characterized by lack of transparency and accountability in the public resources management. According to [10] the civil crisis in Liberia led to the collapse of PFM institutions, failure of systems and deteriorated human capacity, which culminated into near complete absence of procedures in the management of public resources. In response, however, the government of Liberia enacted a PFM Act in 2009 and further instituted a PFM steering committee to undertake the strategic oversight and coordination of the country's PFMR agenda. In addition, the government rolled out an Integrated Financial Management Information System (IFMIS) as a budget management and accounting system to improve public expenditure and management process. The IFMIS uses modern Information and Communication Technologies (ICT) to enhance greater accountability and transparency across all government departments, agencies and public organizations [10].

In Kenya, the new constitution promulgated in 2010 positioned fiscal decentralization and PFM at the center of public financial management policy reforms to ensure both fiscal efficiency and discipline in the use of public finances. The PFMR introduced a different way of managing public resources to enhance public service efficiency and safeguard the available resources to be used in the best interest of the people [43]; [24]; [32]. As such, there is a PFM Act No. 18 of 2012 created to achieve a better PFM as envisioned under public finance, chapter 12 of the constitution. The Act is an Act of Parliament meant to provide for effective management of public finances by national and county governments. The PFM Act and the constitution of Kenya 2010 exemplify both national and county governments as autonomous and interdependent institutions each entrusted with the duty to formulate, plan, implement and report their budgets and plans without interference of the other. In this regard, there exists a Commission for Revenue Allocation (CRA) 
entrusted with the responsibility of allocation financial resources to county governments, state organs and other public organizations. Besides, the office of the Controller of Budget also undertakes audits of the governments and makes recommendations based on the fair and honest opinion about the performances achieved by each public organization. The pursuit of PFMR aims at enhancing accountability, public participation, equitable sharing of revenue, tax burden, debt burdens/benefits, equitable development, as well as prudent and responsible use of public resources, responsible financial management and clear fiscal reporting. Since the PFM reforms ensued in Kenya, the country has seen a number of changes in budget formulation, public participation, procurement, external audit, revenue collection, budget execution, and parliamentary oversights [43].

\subsubsection{Budget Implementation}

Budgets are necessary in every aspect of human or organizational life without which, both personal or organizational interests, aspirations, goals and objectives can hardly be achieved. The budget is the basis of financial planning that helps to monitor, control and guide an economy towards planned development and ensures efficient and effective resource utilization [1]. The budget is a detailed quantitative estimation of an organization's expenses and revenues, or internal and external cash flows for a specified future period, reflecting the gains, interests, and expectations [23]. It is an effective tool for planning, coordinating, monitoring, controlling resource movements, decision making, performance evaluation and communication. The success of any organization depends on the effectively and efficiently of its budgeting. However, budget implementation can be challenging to many public organizations since such institutions are required to make accurate forecasts for the execution of certain programs and development projects using economic parameters [17]. Besides, it can be difficult, especially when unforeseen needs or costs cause fluctuations in the flow of resources. In such cases, it is very necessary to conduct budgetary reviews to identify budget variances and to ensure effective implementation. Studies have been done on budget preparation, implementation and reforms [36]; [1]; [17]; [24].

As [1] studied the obstacles of preparing and implementing budgets in Jordan, it was established the lack of understanding about the necessity of budgets and unrealistic estimations as impediments to budget preparation and execution. [36] study of Nigerian budget implementation reforms established that poor project conceptualization, design and planning practices impacted resource management and that poor budget implementation constrained the achievement of development goals as evidenced by many abandoned projects. [28] The problems related to budget implementation can best be addressed through budgetary reforms under New Public Management framework that entails Performance Budgeting and incorporates planning into the entire budgeting process. Such problems include fund disbursement delays, budget execution delays, wrong prioritization, operational inefficiencies, misappropriation of resources, lack of capacity and corruption. Effective budget execution requires much focus on the organization's performance indicators and management systems to address the implementation problems. According to [24] effective budget implementation helps improve the comprehensives of budget operations, building better links between annual allocations and medium-term policy objectives. In Kenya, Budget implementation by the county governments follow the approval of each county's supplementary budget entailing both recurrent and development expenditure. In order to finance the budget, the Kenyan city counties and all other county governments expect to receive finances raised from equitable share of revenues raised nationally, conditional and unconditional grants and to generate local revenues. On budget implementation, each county entrusts economic sectors with the duty to deliver services that meet the needs of the citizenry. Such sectors of the economy vary in number and functions from county to county and are established by law depending on the public needs for which the county governments are expected to serve.

\subsubsection{Kenyan City Counties}

According to the Urban Areas and Cities Act 2011, a city is any area conferred the status of a city while a city county refers to a city which is also a county [30]. In Kenya, the County Governments Amendment Act supplement number 34 of 2016 outlines three incorporated and gazetted city counties including Nairobi City county, Mombasa city county and Kisumu city county. These, among other counties are devolved governments that operate autonomously with some interdependence with the national government. There are a total of 47 county governments in Kenya out of which only the aforementioned three counties are classified as citycounties. The devolved governments were established to address among other issues, inequitable distribution of resources, accountability issues, enhance public participation in public policy issues, to hasten socio-economic empowerment of the citizens, enhance equity in regional and national development. The counties emerged as a result of reforms in governance to address the needs and interests of the people. However, all the county governments have their budgets largely funded by the equitable share of national revenues from the national government, additional allocations (conditional or unconditional) from the national government's share of revenues, locally generated resources, debt financing, grants, foreign investment partners and donors. The counties often prepare their consolidated annual budgets, budget policy documents, fiscal policy papers and the corresponding implementation plans which are submitted to the national government whereupon the (CRA) allocates the resources [11]. The CRA in consultation with other stakeholders thus reviews and evaluates the budget proposals and allocates resources equitably to the county governments based on every county's population, contribution to the national cake, poverty levels, land area covered by the county 
and fiscal responsibility among other factors. In this regard, the CRA formula for revenue allocation to the county governments considers the said parameters that guide the sharing of state resources. The CRA formula sis as follows:

$$
\mathrm{CA}_{\mathrm{i}}=0.45 \mathrm{PN}_{\mathrm{i}}+0.26 \mathrm{ES}_{\mathrm{i}}+0.18 \mathrm{PI}_{\mathrm{i}}+0.08 \mathrm{LA}_{\mathrm{i}}+0.02 \mathrm{FE}_{\mathrm{i}}+0.01 \mathrm{DF}_{\mathrm{i}}
$$

Where: $\mathrm{CA}=$ Revenue Allocated to county; $\mathrm{I}=$ County 1 , $2, \ldots 47 ; \mathrm{PN}_{\mathrm{i}}=$ Revenue Allocated to a county on the basis of population factor; $\mathrm{ES}_{\mathrm{i}}=$ Revenues allocated to a county on the basis of Equal Share factor. This is shared equally among the 47 counties; $\mathrm{PI}_{\mathrm{i}}=$ Revenue allocated to a county on the basis of Poverty Factor; $\mathrm{LA}_{\mathrm{i}}=$ Revenue allocated to a county on the basis of the Land Area Factor; $\mathrm{FE}_{\mathrm{i}}=$ Revenue allocated to a given county on the basis of Fiscal Effort; $D_{i}$ $=$ Revenue allocated to a given county on the basis of Development Factor.

Once the revenues are allocated and disbursed, the counties execute their respective budgets. While the budgetary allocations vary depending on the socio-economic factors, it has been witnessed that the performance achievements also vary per county. Table 1 shows the annual revenue allocations made to the Kenyan city counties for the entire period that the county governments have been constitutionally functional. The said budgetary allocations cater for among other things, recurrent and development expenditure. In particular, the CRA itemized the allocations to such areas as level five hospitals, refurbishment of county offices, leasing of equipment, free maternal health care, compensation for user fees foregone, fuel levy fund, emergency fund.

Table 1. Total Allocations to County Governments (Equitable \& Conditional Transfers).

\begin{tabular}{llll}
\hline $\begin{array}{l}\text { County/ } \\
\text { Financial Year }\end{array}$ & $\begin{array}{l}\text { Mombasa City County } \\
\text { (Ksh) }\end{array}$ & $\begin{array}{l}\text { Nairobi City County } \\
\text { (Ksh) }\end{array}$ & $\begin{array}{l}\text { Kisumu City County } \\
\text { (Ksh) }\end{array}$ \\
\hline FY 2012/13 & $257,348,388$ & $551,081,044$ & $275,559,579$ \\
FY 2013/14 & $4,347,575,931$ & $9,896,236,826$ & $4,866,678,745$ \\
FY 2014/15 & $4,876,499,637$ & $12,945,531,236$ & $5,416,106,404$ \\
FY 2015/16 & $5,920,733,428$ & $13,633,213,384$ & $6,334,176,498$ \\
FY 2016/17 & $6,309,693,626$ & $14,614,500,87$ & $6,811,407,625$ \\
TOTAL & $21,711,851,011$ & $51,640,563,367$ & $23,703,928,851$ \\
\hline
\end{tabular}

Source: [11].

\subsection{Statement of the Problem}

The government of Kenya has undertaken various PFM reforms to enhance the effectiveness of PFM. These initiatives are founded on legislations and acts of parliament that are usually subjected to review. The PFMRs are widely promoted considering that the public sector has been organized on wrong principles, faces corruption, experiences fiscal inefficiencies, misappropriation of resources and poor management of public funds thus the need for reinvention and institutional renewal. Despite the PFMRs undertaken, the Kenyan county governments have been reporting dismal performance evidenced by low absorption of recurrent and development budget estimated at $39.8 \%$ and $26.1 \%$ respectively despite the expected absorption rate of $50.0 \%$. Besides, a report from the office of the controller of budget indicates that out of the Ksh. 119.29 billion issued by the Exchequer for half of the financial year 2014/2015, only Ksh.103.7 billion were utilized yet part of the expenditure could not be accounted for. Considering that the reforms are undertaken to enhance transparency, increase fiscal discipline, enhance economic performance, and devolution of government activities, to address the gaps identified, especially inadequate strategy orientation and lapsed development strategy, this study seeks to determine the influence of PFMRs on budget implementation by the Kenyan City Counties. In tandem, studies have been done on PFMRs [16]; [24] and [32]. [16] studied the reform of the public administration of Singapore while [24] examined the effect of public financial management reforms on effective management of public funds in Kenya. [32] also assessed the correlation between PFMR and economic performance of the Kenyan public sector. None of these studies focused on the influence of PFMRs on budget implementation by Kenyan city counties hence the need for the study.

\subsection{Specific Objectives of the Study}

1 To examine the influence of IFMIS Re-Engineering on budget implementation by Kenyan city counties

2 To establish the influence of fiscal decentralization on budget implementation by Kenyan city counties

\subsection{Research Hypotheses}

$1 \mathrm{H}_{0}$ : IFMIS re-engineering has no significant influence on budget implementation by Kenyan city counties

$2 \mathrm{H}_{0}$ : Fiscal Decentralization has no significant influence on budget implementation by Kenyan city counties

\subsection{Significance of the Study}

This study examined the relationship between public financial management reforms and budget implementation by Kenyan city counties. This study was considered useful, not only to the Kenyan city counties, but to all the 47 county governments in Kenya as its recommendations could guide the achievement of efficient and effective public budget implementation. The study was also taken to be pivotal to the national government from where resources are allocated and disbursed, the office of the controller of budget and county chiefs as it highlighted important correlates of effective 
budget implementation. In addition, sectoral accountants, county treasury staff, public policy implementors and public resources managers also had to gain significantly as the study provides managerial insights into successful budget executions. Besides, scholars and researchers in the field of finance stand to benefit from the study as it builds critical literature on budgeting and public financial management.

\subsection{Scope of the Study}

The study was conducted in all the three Kenyan city counties namely Nairobi city county, Mombasa city county and Kisumu city county. It involved employees from each county's treasury, budget offices, directorate of economic planning, IFMIS officers as well as sectoral accountants from sectoral departments. The study covered statistics for the period 2013-217 and was done over a six-month period from April, 2017 to September, 2017.

\subsection{Limitations of the Study}

The study was limited by the heightened political activities ahead of the august $8^{\text {th }}$ general elections. Considering the political tension that ensued after the announcement of the presidential results, movement across the counties wasn't easy and hence the collection of primary data was partly constrained. Given the varying sectoral arrangement of each city county, the researcher noted that the research settings were not purely homogeneous and hence chose to use a judgmental sampling technique to select the participants. Suspicion by a few respondents regarding the purpose of the study and fear of victimization was also noted. As such, the researcher clarified to the respondents that the required data were meant for academic purposes only and the participants were assured of utmost confidentiality regarding their identities. Also, the interpretation of the study findings was confined to the data provided by the respondents and the secondary data obtained from financial reports and the findings were generalized and construed to relate to all the Kenyan city counties.

\section{Literature Review}

\subsection{Theoretical Review}

\subsubsection{Modern Portfolio Theory}

The Modern Portfolio Theory (MPT) is a theory of portfolios choice developed by Harry Markowitz [34]. The MPT is a sophisticated investment decision approach that aids in classifying, estimating and controlling both the kind and amount expected risk and return. There are a number of government activities and projects that can be organized into portfolios, each with its own budget consistent with the MPT used in financial decision making and asset management under conditions of risk and uncertainty [23]. The theory attempts to maximize portfolio expected return for a given level of portfolio risk or equivalently minimize risk for a given level of expected return, by carefully choosing proportions of various assets [15]. This implies that for the
Kenyan city counties, combining different investment options whose returns are not perfectly positively correlated, MPT seeks to reduce the total variance of the portfolio return while assuming that investors are rational and markets are efficient. The MPT formulates the concept of diversification in investing with the aim of selecting investment assets having collectively lower risks than any individual asset. With regards to budgetary allocations and appropriations, the MPT aids the city county governments in describing investment options in terms of the inherent risks and expected returns, determining the allocation of resources among classes of investments or budget items, reconciling risks and returns and measuring performance. Investors thus choose to invest in portfolios that reduce their exposure to individual asset risk by holding a diversified portfolio of assets.

\subsubsection{Stakeholder Theory}

The stakeholder theory was developed by Richard E. Freeman in 1984 as an approach that seeks to introduce business-based ideas to the mansagement and administration of the public sector. According to this theory, a stakeholder refers to a person or group who can affect or be affected by the achievement of the organization's objectives. The theory presents an approach by which public decision-makers scan their environments in search of opportunities and threats. In this regard, budget participants and public financial management reforms implementation agents undertake detailed environmental scan on the social, political and economic sectors in search of opportunities and threats to growth and development in order to prioritize the appropriation of public resources across various elements of the public budget policy. According to [18] an organization's effectiveness is measured by its ability to satisfy not only the stakeholder, but also the agents who have a stake in the organization. This satisfaction comes when the stakeholders are sufficiently engaged and involved in organizational decision-making and policy implementation. As [35] observes, the entire budgeting process should enlist the input and participation of as many stakeholders as possible for the organizational executives to keep the interest of all stakeholders aligned in the same direction since theory's core function is to balance the interests of all stakeholders. The theory has three aspects that mutually support each other; the instrumental approach, normative approach and descriptive approach. The instrumental approach identifies the connection between organizational goals while the normative approach identifies the moral guidelines for operations and policy implementation as the descriptive approach explains the organizational characteristics and behaviours [13].

\subsubsection{Resource-Based Theory}

The resource-based view is a widely cited and an influential management theory that explains the internal sources of an organization's sustained competitiveness. The theory has been established from its prime foundation by 
Penrose, who provides a logical explanation of the causal relationships between organizational resources, production capability and overall performance. According to [39] the theory is chiefly concerned with organizational efficiency and innovative utilization of resources. In the case of the context of this study, there are a total of 47 counties in Kenya which even though all of them are classified as county governments, they are endowed with uniquely varying resources, operate in different settings to serve varied the needs of the Kenyan citizenry and exhibit varying performances. In fact, the proponent of this theory avers that the productive resources controlled by organizations could vary significantly from one entity to another and in the same sense organizations are perceivably fundamentally heterogeneous even if they are in the same industry or category. This theory further views resources and products generated by the said resources as two sides of the same coin. Among the most important resources any organization requires to gain competitive advantage are intellectual capital, financial resources and firm-specific assets which of course have to be inimitable, tacit in nature, synergistic and not substitutable. This theory postulates that every organization that seeks to achieve excellent performance must be able to assemble and exploit an appropriate combination of the said resources. In the context of budget execution by the Kenyan city counties, this makes it possible for policy stakeholders, budget staff, county leadership, economic planners, project implementors and other stakeholders to understand how the available resources can be utilized to improve organizational performance.

\subsection{Empirical Review}

\subsubsection{IFMIS Re-Engineering}

One of the most common PFM reform practices involves the adoption of the Integrated Financial Management Information system (IFMIS) among other Enterprise Resource Planning (ERP) systems. The IFMIS is an automated information system that interlinks planning, budgeting, expenditure, management and control, accounting, audit and reporting. IFMIS refers to the computerization of public expenditure management processes, including budget formulation, budget execution and accounting with the help of fully integrated system for financial management [33]. In its basic nature, the IFMIS initially incorporated only a few modules while other PFM practices remained manual [8]. Such modules included general ledger, budgetary accounting, accounts payable, accounts receivable, cash management, e-Procurement, fixed assets and non-core systems including payroll system, budget development and project ledger [33]. To introduce a full cycle end-to-end integrated approach for PFM, [22] notes that developing countries adopt IFMIS re-engineering to promote efficient and effective PFM, accountability, reduce fraud, enhance security of data management and comprehensive financial reporting and better public service delivery. According to [8] IFMIS encompasses internal and external dimensions that enhance service delivery to citizens, businesses and other stakeholders as it holds the potential for improving public administration. It also strengthens financial controls, facilitates a full and updated picture of commitments and expenditure on a continuous basis hence making interactions between the Government and Citizens (G2C), Government and Businesses (G2B) as well as Government to Government (G2G) more friendly and convenient. IFMIS enables efficient resource allocation mechanisms, improves management of information for decision-making and improves financial controls by availing reliable and timely financial information. In addition, it uses standard data classification for recording financial events, transaction processing and reporting and tracking financial events and summarizing financial information. It also supports policy decisions, management reporting, fiduciary responsibilities and the preparation of auditable financial statements. Moreover, the system also guides the transition of tasks in PFM process from budget preparation and execution to accounting and reporting. According to [33] the IFMIS is prime and highly customized to suit various working environments as it is modelled around an accounting system to operate as per the needs of the environment where it is installed.

A number of empirical studies done on IFMIS adoption and implementation support the above literature [8]; [43]; [21]; [28] and [32]. Reference [12] carried out a study seeking to explore the effects of IFMIS publishing budget data from public finance websites of 198 economies. The study sought to identify potential areas of improvements in budget transparency and further provide guidance on effective use of IFMIS platforms on open budget data publishing. The study findings revealed that despite the wide availability of financial management information systems used by 198 governments globally, only 24 countries had evidence of good budgetary practices. [22] also examined the guidelines for effective implementation of IFMIS by the Public sector of South Africa. The study sought to identify the challenges and risks involved in the implementation of the IFMIS in South Africa. Some of the challenges identified in the study include lack of capacity, lack of commitment, as well as institutional and technical challenges. The study also recommended capacity building programmes, stakeholder commitment, establishment of an effective change management team and an elaborate implementation plan for successful IFMIS adoption.

Also, a study on the impact of IFMIS on economic development in Ghana using a case study research design focused on the Ghana IFMIS using both qualitative and quantitative data spread over a 10 year period from the Ministry of Finance and Economic Planning [3]. The study considers among other economic performance indicators, the Gross Dometic Product (GDP), economic growth and resource allocation. The study findings revealed that much of the country's economic performance relies on the efficiency of the public and private sectors, government fiscal policies, interest rates and the regulatory environment. Considering that IFMIS was implemented for the first time in Kenya in 
2003 and further re-engineered in two phases with the first phase running through 2011-2013 and the second phase from 2013-2018 components, it is not a first-time innovation in the country. According to [33] IFMIS re-engineerig comprised of many components including: Re-engineering for business results for improved financial management; Planto-budget system for planning, policy objectives and budget allocation; procure to pay system for supply chain management; revenue to cash system for auto-reconciliation of revenues and payments; record to report system to interface with the Central Bank of Kenya (CBK); ICT to support and communicate to change systems for better performance. [8] also studied the impact of IFMIS on financial probity in the public sector in Kenya using the Ministry of Foreign Affairs as a case. The study used a case study design and drew from both agency theory and systems theory and relied on 40 IFMIS users the ministry of foreign affairs. The study findings indicate that $74.8 \%$ of the financial performance of the public sector can be attributed to the adoption of IFMIS re-engineering. In addition, the study established that IFMIS implementation affects the overall procurement performance in government ministries in Kenya where management commitment, capacity and training and the level of IFMIS adoption positively influence financial probity.

\subsubsection{Fiscal Decentralization}

Fiscal decentralization is a process through which a central government devolves upon sub-national governments decision-making powers, authority over and responsibility for various aspects of public finance [26]. Some of the most important aspects of public finance that are decentralized to devolved units of governments relate to revenue, expenditure, borrowing and fiscal policy. In a fiscally decentralized state, the national government controls only the central government finance while the devolved governments are completely responsible for all aspects of devolved public finance aiming to deliver public services more efficiently and effectively. This study details the effect of fiscal decentralization on public budget implementation. A study done by [27] reviewing the impact of fiscal decentralization on the economy, society and politics examines the proper measurement and the potential endogeneity of fiscal decentralization. The study also takes into account the impact of fiscal decentralization reforms on political institutions using a survey that presents a balanced view of what is known and what is yet to be known hence opening room for further research on fiscal decentralization. The study findings depict much optimism about the success of decentralized fiscal systems as has reportedly been witnessed in many parts of the world especially where fiscal decentralization is well designed and implemented. Another study [6] relating fiscal autonomy with spending efficiency of local governments in Italy notes that economies around the world, executing financial reforms seek to increase fiscal autonomy of the lower tiers of governments. Such governments also purpose to align spending with funding responsibilities and hence increase their efficiency in provision of essential public services. The study used a sample of 262 Italian municipalities in Turin province to investigate the role played by tax decentralization, as measured by the degree of fiscal autonomy in covering the costs of providing essential public services. Relying on non-parametric (DEA) and paramentric (SFA) frontier techniques to examine efficiency performances and related determinants, the findings showed that autonomous municipalities with higher share of current spending covered by own taxes exhibit less inefficient behaviours. The study also indicates that the strictness of budget constraint due to some fiscal discipline rules enhances spending efficiency hence the need for reforms tending to tax decentralization.

In a study done by [31] investigating the relationship between fiscal decentralization and budget deficits in Turkey using panel data techniques, strong empirical evidence shows that expenditure decentralization has significant negative correlation with budget deficits. This is in tandem with the findings of a study [25] done in Indonesia investigating the effects of the Indonesian decentralization and democratization process on budget allocation at the subnational level. In addition, the study indicates that country size significantly re-inforces the said relationship in terms of lowering budgetary deficits. The study also presents significant evidence justifying negative effect of revenue decentralization on budget deficits only when there is good governance. However, the study findings call for a caution about immediate policy recommendations towards higher fiscal decentralization. [40] studied the effect of fiscal decentralization on under-five mortality in Iran by examining the relationship between fiscal decentralization indicators and health outcomes. The study assessed the effect of fiscal decentralization in medical universities and fiscal decentralization in provincial revenues on the under-five mortality rates in the Iranian provinces over the period between 2007-2010 using panel data methods and established cross-sectional dependency amongst the studied variables. The findings, however, revealed negative impact of fiscal decentralization in the health sector son the mortality rate. It also showed a negative correlation between the underfive mortality and the density of physicians, hospital beds, and provincial GDP per capita, but a positive relationship with Gini co-efficient, urbanization and unemployment. It is on this basis that the study supported fiscal decentralization in the health sector and cautious implementation of development policies.

In addition, [14] studied how fiscal decentralization and public service delivery relate in South Africa using provincial level data from South Africa. The study examined how fiscal decentralization impacts basic service delivery, focusing on own-source revenue since South Africa is predominantly a state characterized by relatively high degree of fiscal decentralizations in terms of expenditure responsibilities and administration. The study established that in South Africa, despite the focus of sub-national government financing on equity and redistribution, huge 
disparities exist across provinces regarding per capita revenue as well as per capita expenditure on health and education. However, the study recommends increased fiscal decentralization and greater revenue autonomy in order for sub-national governments to improve service delivery by enhancing transparency and shifting accountability to citizens.

In Kenya, [43] studied the impact of public finance management reforms on financial performance of commercial state-owned enterprises using a descriptive survey research design with a sample of 30 out of 168 commercial state enterprises. The study relied on both primary and secondary data and established that the credibility of budgets influence the financial performance of the state owned commercial organizations to a great extent. The study findings also revealed that the comprehensiveness and transparency of the decentralized budget greatly influenced the financial performance of the organizations. Further, the study findings showed that the predictability and control exercised in budget execution had significant impact on the financial performance of the stateowned enterprises. Policy based budgeting, accounting, recording and financial reporting in the organization also impacted the financial performance of the organizations to a great extent. Concurring with [5] fiscal decentralization in form of Constituency Development Fund (CDF) in Kenya promotes allocative efficiency and equity, but at a cost of exporting tax burdens from capital projects to the central government. As a result, the study recommended a expansive implementation of PFMRs to other governmentowned organizations to enhance their performance achievements.

\subsubsection{Budget Implementation}

According to [1] the budget is the basis of financial planning that helps to monitor, control and guide the economy towards planned development through efficient and effective resource utilization. The budget is detailed quantitative estimation of an enntyty's expenses and revenues, or internal and external cash flows for a specified future period reflecting the gains, interests, and expectations [23]. It is an effective tool for planning, coordination, monitoring, controlling resource movements, decision making, performance evaluation and communication as it helps in utilization of the available human, financial and physical resources. The success of any organization depends on how effectively and efficiently the budget is planned and executed. However, budget implementation is challenging to many public organizations since such institutions are required to make accurate forecasts for the execution of certain programs and development projects using economic parameters [17]. Besides, budget implementation can be difficult, especially when unforeseen needs or costs cause fluctuations in flow of resources. In such cases, it is very necessary to conduct budgetary reviews to identify budget variances to ensure effective implementation. A number of studies have been done on budget preparation, implementation and reforms [36]; [24]; [4] and [41].

[41] examined the result-oriented financial management reforms using lessons from Australia and Britain with a critical focus on result-based budgeting and reporting. The study evaluated the influence of parliamentary control, political accountability, the role of managers, political decision-making process, financial control and critical factors of success or failure on budget execution. The study recommended sufficient attention to education and training as a means of enhancing the competencies of the persons involved in budget execution, a good monitoring system and periodic budgetary evaluation and adjustments for efficient and effective budget execution. Another study on how far PFMRs have come in Africa, focused on the strength of PFM systems in 31 governments [4]. The study examined the patterns of strengths and weaknesses across the countries' PFM systems and established that budgets are made better than they are executed citing that the budget implementation practice lags behind the creation of processes and laws. This implied that the budget preparation processes are comparatively stronger than budget executions and thus recommended adjustments in reform approach. [36] analyzed the impact of the budget implementation and control reforms of the federal government of Nigeria on resource management, level of productivity and efficiency as well as personnel and overhead costs. The study relied on an ex-post facto descriptive research design and used a structured 5point Likert scale questionnaires to collect data from accountants and economists in the federal civil service. The findings of the study revealed that poor project conceptualization, design and planning practices by ministries, departments and agencies impacted resource management and that poor budget execution constrained the achievement of development goals as evidence by many abandoned projects as noted in [29]. The study further concluded that the budget being a veritable tool for planning, controlling, communicating, decision-making and value creation, the government should ensure that all ministries, departments and agencies abide strictly by the budget implementation reform strategies. It was also noted that the effectiveness of Medium Term Revenue Framework (MTRF), Medium Term Expenditure Framework (MTEF) and other budgetary reform strategies of the federal government are achievable through budget discipline, yet a lot still need to be done on financial and performance audit of budgetary allocations, timely publication and implementation of the audit reports.

[24] studied the effect of public financial management reforms on effective management of public funds in Kenya using the National treasury as a case. The study relied on a descriptive research design using a stratified random sampling technique and a regression model to determine the relationships between the identified variables. The study established that procurement reforms greatly influenced effective public fund management followed by budgeting reforms and adoption of IFMIS. It was noted in the study 
findings that effective budget implementation helps improve the comprehensiveness of budget operations, building better links between annual allocations and medium-term policy objectives. In addition, the study also recommended that budget implementation should focus on the organization's performance indicators, management systems and involve all stakeholders in order to tackle execution impediments such as fund disbursement delays, budget execution delays, wrong prioritization, operational inefficiencies, misappropriation of resources, lack of capacity and corruption.

\subsection{Conceptual Framework}

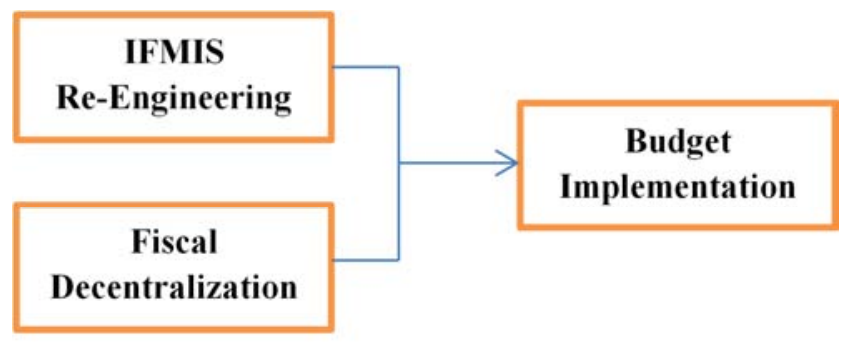

\section{Independent Variables Dependent variable}

Figure 1. Conceptual Framework.

\section{Research Methodology}

\subsection{Introduction}

A research methodology is a procedure by which researchers go about their work of describing, explaining and predicting phenomena [38]. This chapter provides a road map and guidelines on how the objectives of this study were achieved. It covers the research design, target population, sampling technique and sample size determination, research instruments, pilot-testing, data collection and data analysis procedure.

\subsection{Research Design}

A research design is a systematic structure that outlines the methodology and procedure for conducting a study on a given topic [45]. The study used an ex post facto descriptive research design to examine the influence of Public Finance Management Reforms on Budget Implementation by Kenyan city counties. This design was preferable for this nonexperimental research since it required the description of what has happened, what is happening and phenomena as they are. The ex post facto descriptive research design was appropriate for examining the relationships among such variables over the specified period.

\subsection{Target Population}

The target population of the study comprised 55 respondents from the county treasuries, budget offices, county public service office, directorate of economic planning, IFMIS department and sectoral accountants for Nairobi, Mombasa and Kisumu city county governments respectively.

\subsection{Sample Size and Sampling Procedure}

A sample is a representative subset of the whole population. Sampling procedure on the other hand, refers to the process of selecting a subset of the population [46].

\subsubsection{Sampling Frame}

A sampling frame is a list of the population from which the sample can be drawn. It refers to that which is used to identify the objects, individuals or elements in each sampling unit [48]. The sampling frame in this study consisted of respective county economists, sectoral accountants and county budget office employees since they are the officers involved in the budget policy formulation, execution and financial reporting as shown in Table 2.

Table 2. Sampling Frame.

\begin{tabular}{lllll}
\hline County/Department & Nairobi City County & Mombasa City County & Kisumu City County & TOTAL \\
\hline Sectoral Accountants & 13 & 10 & 11 & 34 \\
Budget Office & 3 & 3 & 3 & 9 \\
County Treasury & 2 & 2 & 2 & 6 \\
County Economist & 1 & 1 & 1 & 3 \\
IFMIS in charge & 1 & 1 & 1 & 3 \\
Target Population & 20 & 17 & 18 & 55 \\
Sample size per County & 13 & 11 & 12 & 36 \\
\hline
\end{tabular}

\subsubsection{Sample Size Determination}

The sample size was determined by the use of Narssiuma's formula which is shown below.

$$
n=\frac{N * C^{2}}{C^{2}+(N-1) e^{2}}
$$

$(\mathrm{n}=$ sample size, $\mathrm{N}=$ Population size, $\breve{\mathrm{e}}=$ tolerable error $(5 \%), C=$ coefficient of Variation $(0.5))$

$$
n=\frac{55 * 0.5^{2}}{0.5^{2}+(55-1) 0.05^{2}}
$$

$\mathrm{n}=36$

\subsubsection{Sampling Proscedure}

The researcher used a judgmental sampling technique to select respondents for the study. The main consideration for determining the sample size was to ensure that the study represents the entire population while at the same time keeping the research manageable. The respective county economists, heads of budget offices, treasury employees, IFMIS officers, county public service accountants and 
various sectoral accountants were therefore sampled.

\subsection{Data Collection Instruments}

Structured questionnaires with closed-ended questions were used to collect data from the sampled respondents from each of the city counties via a drop-and-pick method, supplemented with interview schedules to obtain more detailed and specific data on the correlates of budget implementation. Besides, the study also relied on data from budget policy documents, fiscal strategy papers, county annual financial reports.

\subsection{Pilot Study}

A Pilot test is a mini-study done in preparation for the main study [50]. It is important in detecting possible errors in the measurement procedures, identification of unclear questions in the questionnaire and determining the validity and reliability of the data to be collected [46]. In this study, employees from Nakuru County treasury and budget office were used for the pilot test. SPSS version 24 was used to analyze the pilot data to determine the validity and reliability of the research questionnaire

\subsubsection{Validity of Research Instrument}

Validity is concerned with whether the research measures what it is intended to measure or rather how true the research findings are [44]. Accordingly, [47] identifies some unsystematic threats to reliability before or during data collection, participants' refusal to cooperate and change of behavior of the participants. Both face validity and content validity tests were conducted on the questionnaire and the objectives clearly defined.

\subsubsection{Reliability of Research Instrument}

Reliability denotes the degree at which a research data is free from error and yields consistent results [49]. Sources of unsystematic threats to reliability include factors due to interviewer error, unfavorable conditions under which measurements are made factors caused by the research subject, instrument reliability and data processing reliability. However, the pilot study helped to test the extent to which the questionnaire could be relied upon. Appropriate wording and formatting of content was done. From the pilot test, a Cronbach alpha $(\alpha)$ with a reliability threshold $(\alpha \geq 0.7)$ was deemed fit and acceptable to test the internal consistency of the questionnaire.

\subsubsection{Reliability Analysis Results}

The pilot results indicated that the research questionnaire met the reliability threshold as shown in table 3 .

Table 3. Reliability Analysis Results.

\begin{tabular}{lll}
\hline Construct & Cronbach's Alpha & No. of Items \\
\hline IFMIS Re-Engineering & .722 & 9 \\
Fiscal Decentralization & .764 & 7 \\
Budget Implementation & .749 & 9 \\
\hline
\end{tabular}

\subsection{Data Collection Procedure}

The researcher obtained permission from the three city county administrations to proceed with data collection. The research questionnaires were self-administered. Data collection sheets were used to obtain secondary data. The study also relied on interviews to obtain first-hand information from judiciously selected IFMIS departmental respondents and also utilized county budget implementation reports, fiscal strategy documents, county outlook papers and other relevant financial reports.

\subsection{Data Processing and Analysis}

Once the required data was collected, the returned questionnaires were cleaned, coded properly and subjected to thorough scrutiny to ensure completeness. The data was analyzed using both descriptive and inferential statistics to determine the relationship between the PFMRs and budget implementation. The researcher used SPSS version 24 to analyze the collected data. Descriptive statistical measures such as percentages, means and standard deviation were used to interpret the study findings. In addition, the researcher did run a linear regression analysis and a Pearson Correlation analysis to show the relationship between the PFMRs and budget implementation. Besides, the descriptive interpretation, tables were used to present the study findings. In addition, the researcher relied on ANOVA to test the hypotheses and the coefficient of correlation was also used to validate the research hypotheses. The following regression equation was used to determine the effect of public financial management reforms on the budget implementation:

$$
\mathrm{Y}=\beta_{0}+\beta_{1} \mathrm{X}_{1}+\beta_{2} \mathrm{X}_{2}+\mathrm{e}
$$

Where: $\mathrm{Y}=$ Budget Implementation; $\mathrm{a}=$ Constant;

$\beta i=$ Coefficients estimated; $\mathrm{X}_{1}=$ IFMIS Re-engineering; $\mathrm{X}_{2}=$ Fiscal Decentralization; $\hat{\mathrm{e}}=$ Error term

\section{Research Findings and Discussions}

\subsection{Response Rate}

According to [42] a response rate represents the number of units in the net sample expressed as a percentage of the units in the gross sample. In this study, the researcher administered all the 36 questionnaires out of which 31 questionnaires were returned and cleaned and only 30 questionnaires were used in the analysis. Therefore, considering the count of all the returned questionnaires relative to those issued, a response rate of $86.1 \%$ was registered.

\subsection{Respondents' Profile}

\subsubsection{Prior Experience in Public Financial Management}

The researcher also sought to find out the extent of the prior experience gained in public finance management by the staff of the identified city counties who were relied upon to provide the require research data. Table 4 shows the 
distribution of the respondents according to their prior experience

The study results shown in table 4 indicate that $33.3 \%$ of the respondents have less than 5 years prior experience in public finance management, $26.7 \%$ of the respondents have prior experience ranging from between 5-10 years in PFM while $16.7 \%$ of the respondents have prior experience of 10 15 years and $23.3 \%$ have over 15 years prior experience in PFM. This implies that the budget policy and execution staff of the Kenyan city counties enjoy a mix of highly experienced and competent Public finance managers

Table 4. Prior Experience in Public Finance Management.

\begin{tabular}{lll}
\hline Prior experience in Public Finance Management & Frequency & Percent \\
\hline 0-5 Years & 10 & 33.3 \\
5-10 years & 8 & 26.7 \\
10-15 years & 5 & 16.7 \\
Over 15 Years & 7 & 23.3 \\
Total & 30 & 100.0 \\
\hline
\end{tabular}

\subsubsection{Work Experience in Budget Policy and Execution}

This study also examined the respondents' work experience in budget policy making and execution. Table 5 shows the distribution of the respondents according to their relevant experience in budget making and execution roles.
Table 5. Work experience in Budget Policy-making and Execution.

\begin{tabular}{lll}
\hline $\begin{array}{l}\text { Experience in Budget Policy-making and } \\
\text { Execution }\end{array}$ & Frequency & Percent \\
\hline 0-5 Years & 9 & 30.0 \\
5-10 years & 12 & 40.0 \\
10-15 years & 5 & 16.7 \\
Over 15 Years & 4 & 13.3 \\
Total & 30 & 100.0 \\
\hline
\end{tabular}

Table 5 shows the respondents' work experience in budget policy-making and execution. Going by the findings, $40 \%$ of the respondents indicated that they have budget policy-making experience spanning between $5-10$ years, $16.7 \%$ of them have $10-15$ years relevant experience while $13.3 \%$ of the respondents have over 15 years relevant experience in budget policy and execution issues. However, only $30 \%$ of the respondents indicated that they have handled budget policy issues for less than 5 years. This implies that majority of the budget implementation staff are properly experienced and thus are competent enough to deliver value to the citizenry.

\subsection{Findings of the Study Variables}

\subsubsection{Descriptive Analysis of IFMIS Re-Engineering}

The analysis in this section is in line with the first objective of the study which sought to find out the perceptions held by the Kenyan city counties on the influence of IFMIS reengineering on budget implementation. Table 6 shows the descriptive statistics and results in details.

Table 6. Descriptive Statistics for IFMIS Re-Engineering.

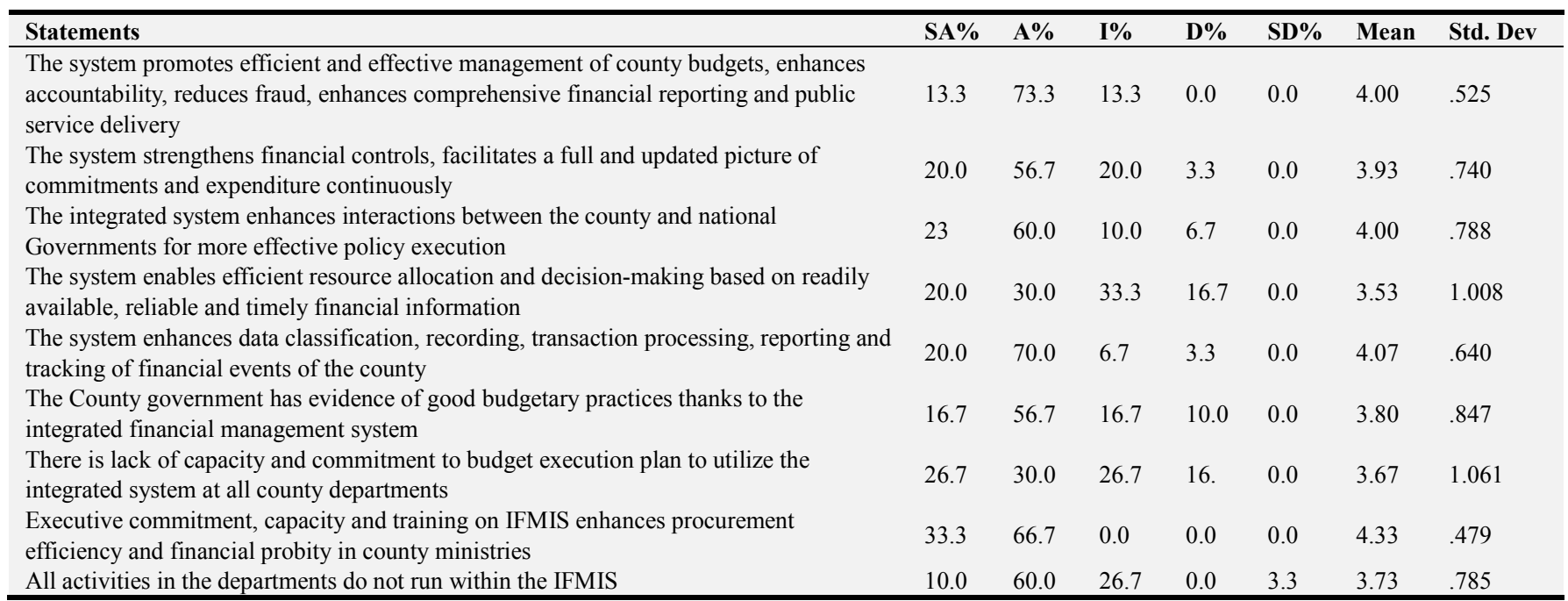

According to the findings of the study, the respondents agreed (mean $=4.0 ;$ Std $\mathrm{dev}=0.525)$ that IFMIS promotes efficient and effective management of county budgets, enhances accountability for resources, reduces fraud, enhances comprehensive financial reporting and public service delivery as observed in a study done by [8] on the impact of IFMIS on financial probity in the Kenyan Public sector. The study also revealed (mean $=3.93$; Std $\mathrm{dev}=0.740$ ) that the system strengthens financial controls, facilitates a full and updated picture of commitments and expenditure continuously and that the respondents agreed $($ mean $=4.00 ; \operatorname{Std} \mathrm{dev}=0.788)$ that it enhances interactions between the county government and national governments for more effective policy execution. However, $75 \%$ of the interviewed respondents indicated that the IFMIS can be very useful when it can function effectively citing its ability to integrate the counties' departmental activities, capacity to generate instant reports and aid in monitoring and evaluation. In addition, the results of the study show that some of the respondents expressed mixed reactions (mean $=3.53$; Std $\mathrm{dev}=1.008)$ regarding the relevance of IFMIS to resource allocation and timely decision making based on readily available financial information. In 
concurrence with [22] the respondents also alluded (mean=4.07; Std $\mathrm{dev}=0.640$ ) that the system enhances data classification, recording, transaction processing, reporting and tracking of financial events of the county and also opined (mean $=3.80$; Std dev=0.847) that the County government has evidence of good budgetary practices supported by the integrated financial management system. Whereas some respondents expressed objection, others indicated (mean $=3.67$; Std $d e v=1.061$ ) that there is lack of adequate capacity to address the integrated system issues at all county departments thereby affecting the overall commitment to budget execution plans and response to emergencies. In this regard, the interviewed respondents revealed that IFMIS suffers malfunctions and system downtimes considering many users from all counties, state departments, parastatals and agencies that rely on it. The study also established that the respondents agreed $($ mean $=4.33 ;$ Std dev $=0.479)$ that sufficient executive commitment, enhanced capacity and training on IFMIS use and operations can enhance procurement efficiency and financial probity in all sectoral departments of the county. From the results of the study, it was also noted that some of the respondents agreed (mean $=3.73$; Std $\mathrm{dev}=0.785$ ) while others expressed objection to the view that not all activities involving finances are undertaken within IFMIS citing system issues and malfunctions beside other challenges.

\subsubsection{Descriptive Analysis of Fiscal Decentralization}

The analysis in this section is in line with the third objective of the study, which sought to establish the perceptions held by the Kenyan city counties regarding the influence of fiscal decentralization on budget implementation. Table 7 shows the detailed descriptive results in this regard.

Table 7. Descriptive Statistics for Fiscal Decentralizationss.

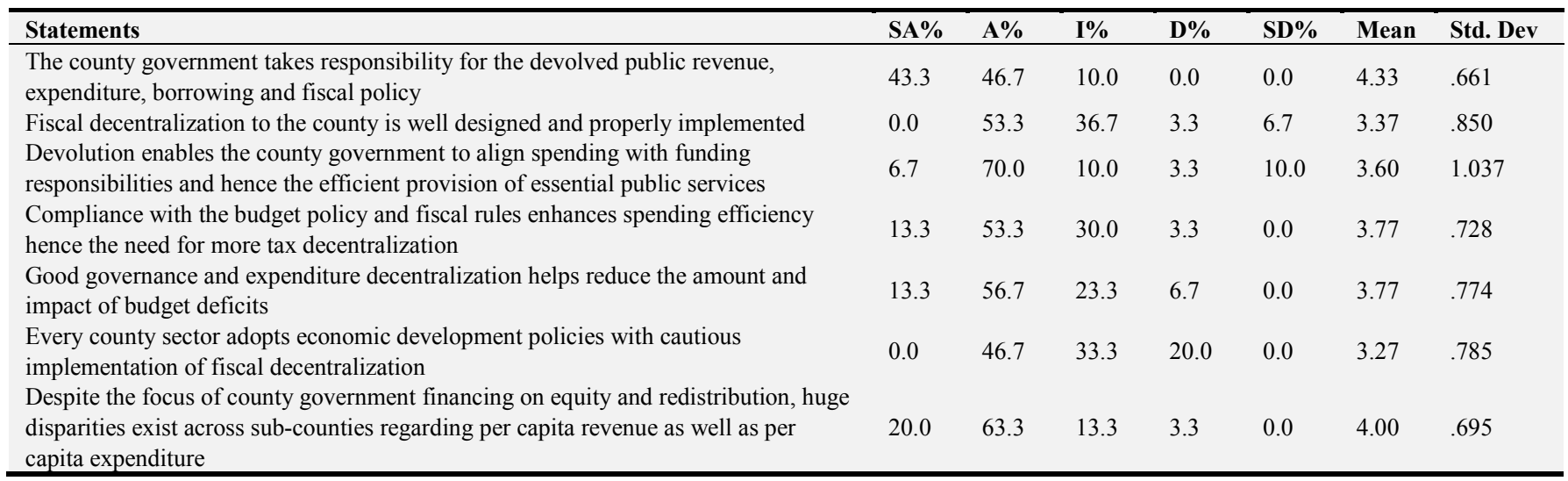

From table 7, the findings of the study established that the respondents strongly agreed $($ mean $=4.33$; Std dev $=.661$ ) that their respective city county governments takes responsibility for the devolved public revenue, expenditure, borrowing and fiscal policy. The study findings also show that the respondents observed (mean=3.37; Std dev=.850) that fiscal decentralization to the counties is well designed and properly implemented. In agreement with the findings of a study done by [31] this study also indicated (mean $=3.77$; Std dev =.774) that good governance and expenditure decentralization helps reduce the amount and impact of budget deficits. Majority of the respondents also agreed (mean $=3.60 ;$ Std dev $=1.037)$ that devolution enables the county governments to align spending with funding responsibilities and hence the efficient provision of essential public services. In accordance with the views of [6], the study findings indicated that the respondents also concurred (mean $=3.77$; Std dev $=.728$ ) that compliance with the budget policy and fiscal rules enhances spending efficiency hence the need for more decentralization of tax. Moreover, the study revealed that the respondents also agreed (mean = 3.77; Std dev =.774) that in the presence of good governance and expenditure decentralization it is possible to reduce the amount and impact of budget deficits as established by [31]. The results of the study also established that the respondents expressed divergent views (mean $=3.27$; Std $\mathrm{dev}=.785$ ) contradicting the notion that every sectoral department adopts economic development policies with cautious implementation strategies. Nonetheless, it also emerged that the respondents strongly agreed (mean $=4.00 ;$ Std dev $=.695$ ) that despite the focus of county governments financing on equity and redistribution, huge disparities exist across sub-counties regarding per capita revenue as well as per capita expenditure.

\subsubsection{Descriptive Analysis of Budget Implementation}

The analysis in this section is in line with the dependent variable which sought to establish the perceptions held by the respondents regarding budget implementation by the Kenyan city counties. Table 8 shows the descriptive results.

Table 8. Descriptive Statistics for Budget Implementation.

\begin{tabular}{|c|c|c|c|c|c|c|c|}
\hline Statements & $\mathbf{S A} \%$ & $\mathbf{A} \%$ & I\% & D\% & SD\% & Mean & Std. Dev \\
\hline $\begin{array}{l}\text { The county budget policy helps in performance evaluation and communication on } \\
\text { available financial and non-financial resources }\end{array}$ & 16.7 & 73.3 & 3.3 & 6.7 & 0.0 & 4.00 & .695 \\
\hline $\begin{array}{l}\text { There is sufficient attention to education and training to enhance the competencies } \\
\text { of the persons involved in budget execution }\end{array}$ & 3.3 & 56.7 & 26.7 & 13.3 & 0.0 & 3.50 & .777 \\
\hline
\end{tabular}




\begin{tabular}{|c|c|c|c|c|c|c|c|}
\hline Statements & SA\% & $\mathbf{A} \%$ & $\mathbf{I \%}$ & D\% & SD\% & Mean & Std. Dev \\
\hline $\begin{array}{l}\text { There exist good monitoring systems for periodic budgetary evaluation and } \\
\text { adjustments for efficient and effective policy execution }\end{array}$ & 13.3 & 43.3 & 30.0 & 13.3 & 0.0 & 3.57 & .898 \\
\hline $\begin{array}{l}\text { Poor project conceptualization, design and planning practices by ministries and } \\
\text { county departments impact expenditure execution }\end{array}$ & 23.3 & 46.7 & 23.3 & 0.0 & 6.7 & 3.80 & 1.031 \\
\hline $\begin{array}{l}\text { Poor budget execution hinders the achievement of development goals as evidence } \\
\text { by many abandoned projects }\end{array}$ & 53.3 & 40.0 & 6.7 & 0.0 & 0.0 & 4.47 & .629 \\
\hline $\begin{array}{l}\text { All ministries, departments and agencies strictly comply with the budget } \\
\text { implementation reform framework }\end{array}$ & 0.0 & 13.3 & 50.0 & 36.7 & 0.0 & 2.77 & .679 \\
\hline $\begin{array}{l}\text { Medium Term Revenue Framework, Medium Term Expenditure Framework and } \\
\text { other budgetary reform strategies of the county government are achievable through } \\
\text { enhanced budget discipline }\end{array}$ & 16.7 & 70 . & 10.0 & 3.3 & 0.0 & 4.00 & .643 \\
\hline $\begin{array}{l}\text { Comprehensive budget operations help in building better links between annual } \\
\text { allocations and medium-term policy objectives }\end{array}$ & 23.3 & 63.0 & 10.0 & 3.3 & 0.0 & 4.07 & .691 \\
\hline $\begin{array}{l}\text { The county leadership often addresses delays in fund disbursement, lack of } \\
\text { capacity and rectifies wrong prioritization of resources. }\end{array}$ & 0.0 & 40.0 & 23.3 & 26.7 & 10.0 & 2.93 & 1.048 \\
\hline
\end{tabular}

The results of the study revealed that the respondents strongly held the view (mean=4.00; Std dev=0.695) that county budget policy helps in performance evaluation and communication on available financial and non-financial resources. As noted in the findings of Sceers, Sterck and Bouckaert (2005), the respondents also agreed (mean=3.50; Std dev $=0.777$ ) that there is sufficient attention to education and training to enhance the competencies of the persons involved in budget execution. The study findings also indicate that the respondents agreed (mean=3.57; Std $\mathrm{dev}=0.898$ ) there exist good monitoring systems for periodic budgetary evaluation and adjustments for efficient \& effective policy execution. However the findings revealed (mean=3.80; Std dev=1.031) that poor project conceptualization, design and planning practices by ministries and county departments impact expenditure execution as revealed by [29] and [36]. Among other factors that influence budget execution, the respondents pointed out to cash flow problems, late initiation of procurement process and hence late initiation of development projects, IFMIS issues, delays in fund disbursement, corruption and lack of political goodwill. It also emerged that the respondents strongly agreed (mean $=4.47$; Std $\mathrm{dev}=0.629$ ) that poor budget execution hinders the achievement of development goals as evidence by many abandoned projects.

In concurrence with the Annual County Governments Budget Implementation Review Report for the financial year 2015/2016, the recurrent expenditure by Nairobi City County accounted for $129.4 \%$ of funds released for recurrent activities while development expenditure accounted for $1,772.8 \%$ of the funds released for development activities. Moreover, the expenses on personnel emoluments during that financial year amounting to Ksh 13.47 billion translated to $56.2 \%$ of the total expenditure contrary to the $35 \%$ limit set by the Public Finance Management Act requirement at the time. Kisumu city county spent Ksh 4.61 billion on recurrent expenditure representing $82.3 \%$ of the annual recurrent budget, which was a decline from $86.6 \%$ the previous financial year. The development expenditure for Kisumu county during the FY 2015/2016 recorded an absorption rate of $45.3 \%$ down from $47.4 \%$ attained the previous financial year. During the same period, Mombasa city county county spent Ksh. 3.99 billion representing $69.1 \%$ of emoluments and $1.2 \%$ decline from the records of the previous fiscal period, yet it still surpassed the limits set by the PFM Act then (Controller of Bugdet, 2016). Table 9 presents the detailed budget execution data for the three Kenyan city counties.

Table 9. Annual County Governments Budget Expenditure Implementation.

\begin{tabular}{|c|c|c|c|c|c|}
\hline & City County & FY 2013/14 (Ksh) & FY 2014/15 (Ksh) & FY 2015/16 (Ksh) & FY 2016/17 (First 9 Months) (Ksh) \\
\hline \multirow{3}{*}{ Actual Recurrent Expenditure } & Mombasa & 5.1 Billion & 5.62 Billion & 5.77 Billion & 4.08 Billion \\
\hline & Nairobi & $15.1^{\prime \prime}$ & $18.72 ”$ & $19.78 ”$ & $13.65 ”$ \\
\hline & Kisumu & $4.43 ”$ & $4.99 "$ & $4.61 ”$ & $3.48 ”$ \\
\hline \multirow{3}{*}{$\begin{array}{l}\text { Actual Development } \\
\text { Expenditure }\end{array}$} & Mombasa & $0.112 ”$ & $2.04 ”$ & $2.77 ”$ & $1.49 ”$ \\
\hline & Nairobi & $1.873 ”$ & $2.3 \%$ & $4.17^{\prime}$ & $1.48 \%$ \\
\hline & Kisumu & $0.989 ”$ & $1.51^{\prime}$ & $1.83 \%$ & $1.13 \%$ \\
\hline \multirow{2}{*}{$\begin{array}{l}\text { Development Expenditure } \\
\text { Absorption Rate }\end{array}$} & Mombasa & $2.4 \%$ & $65.7 \%$ & $82.4 \%$ & $37 \%$ \\
\hline & Kisumu & $4.0 \%$ & $47.4 \%$ & $45.3 \%$ & $36.5 \%$ \\
\hline
\end{tabular}

Source: Office of the Controller of Budget.

Besides, the study findings revealed that the respondents indicated (mean=2.77; Std dev=0.679) an objection and indifference to the view that all ministries, departments and agencies strictly comply with the budget implementation reform framework. The results further indicated that the respondents agreed (mean $=4.00 ;$ Std $\operatorname{dev}=0.643)$ that
Medium Term Revenue Framework, Medium Term Expenditure Framework and other budgetary reform strategies of the city county governments are more achievable through enhanced budget discipline. It also emerged from the findings that the respondents opined (mean $=4.07$; Std $\mathrm{dev}=0.691$ ) that comprehensive budget 
operations help in building better links between annual allocations and medium-term policy objectives. The study also established (mean=2.93; Std $\mathrm{dev}=1.048)$ that the participants had the perception that the government leadership does not always address delays in fund disbursements, lack of capacity and occasionally rectifies wrong prioritization of resources to meet the varied needs of the stakeholders. According to the findings of the study, the respondents indicated that some of the factors that influence budget execution relate to cash flow problems, late initiation of procurement process and hence late initiation of development projects, IFMIS issues, delays in fund disbursement, corruption and lack of political goodwill among others.

\subsection{Inferential Analysis}

This study majorly emphasized on how public financial management reforms influence budget execution by the Kenyan city counties. In particular, the PFMRs examined in this study include IFMIS Re-Engineering, parliamentary oversight, fiscal decentralization and public participation. Correlating each of the said PFMRs with Budget Implementation enabled the researcher to determine the relationships between each independent variable and the dependent variable of the study. Further, the researcher did a multiple regression analysis to assess the relationship between public financial management reforms and budget implementation.

\subsubsection{Relationship Between IFMIS Re-Engineering and Budget Implementation}

This section outlines the results of correlation analysis between IFMIS Re-Engineering and Budget Implementation (Table 10). The findings are interpreted and discussed accordingly.

Table 10. Correlation between IFMIS Re-Engineering and Budget Implementation.

\begin{tabular}{lll}
\hline & & Budget Implementation \\
\hline \multirow{2}{*}{ IFMIS Re- } & Pearson Correlation & .202 \\
Engineering & Sig. (2-tailed) & .284 \\
& $\mathrm{~N}$ & 30 \\
\hline
\end{tabular}

**. Correlation is significant at the 0.05 level (2-tailed).

The results of the study show that there is a weak, positive and statistically insignificant $(\mathrm{r}=0.202 ; \mathrm{p}>0.05)$ relationship between IFMIS Re-Engineering and Budget Implementation. The findings contradicted the findings of [8] indicating that even though IFMIS re-engineering is perceivably an important innovation meant to enhance accountability, eliminate fraud, facilitate accurate recording and processing of financial information besides other pros, it has not lived to its expectations considering a number of the identified shortcomings. The interviewed respondents indicated that despite its perceived benefits, IFMIS has not enhanced service delivery as expected. Some large and longterm projects done in phases are affected by lapse in transaction processing and release of funds due to the shortcomings attributed to the IFMIS.

\subsubsection{Relationship Between Fiscal Decentralization and Budget Implementation}

This section outlines the results of correlation analysis between Fiscal Decentralization and Budget Implementation (Table 11).

Table 11. Correlation between Fiscal Decentralization and Budget Implementation.

\begin{tabular}{lll}
\hline & & Budget Implementation \\
\hline \multirow{2}{*}{ Fiscal } & Pearson Correlation & $.602^{* *}$ \\
Decentralization & Sig. (2-tailed) & .000 \\
& $\mathrm{~N}$ & 30 \\
\hline
\end{tabular}

**. Correlation is significant at the 0.05 level (2-tailed).

The study revealed that the relationship between fiscal decentralization and Budget Implementation was strong, positive and statistically significant $(\mathrm{r}=0.602 ; \mathrm{p}<0.05)$. Concurring with [6], the findings of this study indicated that more decentralization of powers, authority and responsibility over finances to the devolved governments enables the Kenya city counties to correct their fiscal imbalances and appropriate the revenues for effective and efficient project execution as budgeted.

\subsubsection{Hypothesis Testing}

$\mathrm{H}_{0}$ : IFMIS re-engineering has no significant influence on budget implementation by Kenyan city counties

Correlation analysis was used to test whether IFMIS Reengineering significantly influenced budget implementation by the Kenyan city counties. The findings indicate that IFMIS Re-engineering insignificantly influenced budget implementation by the Kenyan city counties $(r=0.202$, $p$ $=0.284, \alpha=0.05$ ). As such, there was insufficient evidence to conclude that there exists a significant linear relationship between IFMIS Re-engineering and budget implementation by Kenyan city counties.

$\mathrm{H}_{0}$ : Fiscal Decentralization has no significant influence on budget implementation by Kenyan city counties

The results on the test of this hypothesis revealed that there was a significant association between fiscal decentralization and budget implementation by Kenyan city counties. The correlation results were $\mathrm{r}=0.602, \mathrm{p}=0.0004$, $\alpha=0.05$ indicating sufficient evidence to conclude that there was a significant linear relationship between fiscal decentralization and budget implementation by Kenyan city counties. This indeed led to the rejection of the null hypothesis and hence confirming the rationale for increased fiscal decentralization in Kenya.

\subsubsection{Relationship Between Public Fiancial Management Reforms and Budget Implementation}

This study assessed how public financial management reforms influenced budget implementation by the Kenyan city counties. Tables 12,13 and 14 show the results of the multiple regression analysis. 
Table 12. Model Summary.

\begin{tabular}{lllll}
\hline Model & R & R Square & Adjusted R Square & Std. Error of the Estimate \\
\hline 1 & $.612^{\mathrm{a}}$ & .375 & .329 & .37898 \\
\hline
\end{tabular}

a. Predictors: (Constant), IFMIS Re-Engineering, Fiscal Decentralization.

Table 12 provides a detailed overview of the results of coefficient of determination $\left(\mathrm{r}^{2}\right)$ and correlation coefficient $(\mathrm{R})$. The results of $\left(r^{2}=0.375\right)$ and $(R=0.612)$ reflected a strong positive correlation between the Public Financial Management Reforms and Budget Implementation by the Kenyan City Counties.

Table 13. ANOVA.

\begin{tabular}{llllll}
\hline Model & & Sum of Squares & Df & Mean Square & Sig. \\
\hline \multirow{2}{*}{1} & Regression & 2.328 & 2 & 1.164 & $.002^{\mathrm{b}}$ \\
& Residual & 3.878 & 27 & .144 & \\
& Total & 6.206 & 29 & & \\
\hline
\end{tabular}

a. Dependent Variable: BI.

b. Predictors: (Constant), Fiscal Decentralization, IFMIS Re-Engineering.

Table 13 presents the findings of analysis of variance (ANOVA) which indicates that the Public Financial Management Reforms significantly influenced Budget Implementation by the Kenyan City counties $(F=8.105 ; p<0.05)$ at $95 \%$ degree of confidence. These findings were based on the adoption of PFMRs to enhance budget execution by the devolved governments with specific interest in the Kenyan city counties.

Table 14. Results of Regression Analysis.

\begin{tabular}{|c|c|c|c|c|c|}
\hline \multicolumn{6}{|l|}{ Coefficients $^{\mathrm{a}}$} \\
\hline \multirow{2}{*}{ Model } & \multicolumn{2}{|c|}{ Unstandardized Coefficients } & \multirow{2}{*}{$\begin{array}{l}\text { Standardized Coefficients } \\
\text { Beta }\end{array}$} & \multirow{2}{*}{$\mathbf{t}$} & \multirow{2}{*}{ Sig. } \\
\hline & B & Std. Error & & & \\
\hline (Constant) & 1.648 & .866 & & 1.904 & .068 \\
\hline IFMIS Re-Engineering & -.182 & .245 & -.130 & -.743 & .464 \\
\hline Fiscal Decentralization & .735 & .193 & .667 & 3.800 & .001 \\
\hline
\end{tabular}

a. Dependent Variable: Buget Implementation.

The outcomes of the regression analysis (Table 14) were interpreted using the regression function:

$$
\mathrm{Y}=\beta_{0}+\beta_{1} \mathrm{X}_{1}+\beta_{2} \mathrm{X}_{2}+\hat{\mathrm{e}}
$$

where $\mathrm{Y}, \mathrm{X}_{1}$, and $\mathrm{X}_{2}$, represented Budget Implementation, IFMIS Re-Engineering and Fiscal Decentralization respectively. The regression results were interpreted as follows:

$$
\mathrm{Y}=1.648-0.182 \mathrm{X}_{1}+0.735 \mathrm{X}_{2}
$$

These findings implied that the researcher failed to reject the first null hypothesis, since there was insufficient evidence to conclude that there was a significant linear relationship between IFMIS re-engineering and budget implementation by the Kenyan City Counties $(t=-0.743$; $\mathrm{p}>0.05)$. The findings also indicated sufficient evidence to conclude that there was a significant linear relationship $(\mathrm{t}=3.800 ; \mathrm{p}<0.05)$ between fiscal decentralization and budget implementation by the Kenyan city counties. This led to the rejection of the second null hypothesis. In sum, the study revealed that though the budget implementation by Kenyan city counties was insignificantly influenced by IFMIS Re-Engineering, it was significantly influenced by fiscal decentralization.

\section{Summary of Findings, Conclussions and Recommendations}

\subsection{Summary of Findings}

As per the study findings, IFMIS can promote efficient management of county budgets, enhance accountability for resources, reduces fraud, enhances comprehensive financial reporting and public service delivery. The study shows that when stable, the system strengthens financial controls, facilitates a full and updated picture of commitments and expenditure continuously and enhances interactions between the city county and national governments regarding policy execution. In addition, it emerged that the use of IFMIS could be relevant to resource allocation and timely decision making based on readily available financial information. The respondents also alluded that the system enhances data classification, recording, transaction processing, reporting and tracking of financial events of the county provide that shortcomings are comprehensively addressed. The results, however, revealed that good budgetary practices exist despite the inadequate capacity to address the integrated system issues at the county level thereby impacting the overall commitment to budget execution plans. The study also 
established that executive commitment, enhanced capacity and training on IFMIS use and operations can enhance procurement efficiency and financial probity in all sectoral departments of the county. From the results of the study, it was also noted that mixed reactions exist as to whether or not all activities involving finances are undertaken within IFMIS citing system issues beside other challenges. It also emerged that development is hindered by the gap between the approved and executed budgets especially due to system dynamics and IFMIS related reasons. The study revealed weak execution capacity by ministries, some governance constraints and in some cases, inappropriate executivelegislative relations as impediments to budget execution while some respondents remained indifferent of made objections to the view.

The findings of the study established that the Kenyan city counties take responsibility for the devolved public revenue, expenditure, borrowing and fiscal policy and that fiscal decentralization to the counties is well designed and properly implemented. The study also indicated that good governance and expenditure decentralization helps reduce the amount and impact of budget deficits and that embracing devolution fully enables the county governments to align spending with funding responsibilities and hence the efficient provision of essential public services. It also revealed that counties comply with the budget policy and fiscal rules thereby enhancing spending efficiency hence the need for more decentralization of tax receipts and other relevant government income. Moreover, the study revealed that in the presence of good governance and expenditure decentralization, it is possible to reduce the amount and impact of budget deficits. However, contradictions emerged on the notion that every sectoral department adopts economic development policies with cautious implementation strategies. It also emerged that despite the focus on equity and resource redistribution, disparities still exist across subcounties regarding per capita revenue and per capita expenditure.

The results of the study revealed that county budget policy helps in performance evaluation and communication on available financial and non-financial resources and that there is sufficient attention to education and training to enhance the competencies of the persons involved in budget execution. It also emerged that there exist good monitoring systems for periodic budgetary evaluation and adjustments for efficient $\&$ effective policy execution. However the findings revealed that in some cases, poor project conceptualization, design and planning practices impact expenditure execution and that poor budget execution hinders the achievement of development goals as evidence by many abandoned projects. Among other factors that influence budget execution, the respondents pointed out to cash flow problems, late initiation of procurement process and hence late initiation of development projects, IFMIS issues, delays in fund disbursement, corruption and lack of political goodwill. Besides, the study findings indicated some objection and indifference to the view that all ministries, departments and agencies strictly comply with the budget implementation reform framework. The results further indicated that the Medium Term Revenue Framework, Medium Term Expenditure Framework and other budgetary reform strategies of the city county governments are more achievable through enhanced budget discipline. It also emerged that comprehensive budget operations help in building better links between annual allocations and medium-term policy objectives. It also emerged from the respondents' perception, that the city counties and national government leaderships do not always address delays in fund disbursements, lack of capacity and occasionally rectifies wrong prioritization of resources to meet the varied needs of the stakeholders in a timely manner. However, a number of changes in budget execution were witnessed including; adherence to the PFM Act, instituting the sectoral budget groups, enhanced oversight and public participation in the entire budget process.

\subsection{Conclusions}

The results of the study showed a weak, positive and statistically insignificant relationship between IFMIS ReEngineering and Budget Implementation. The findings revealed that although IFMIS re-engineering is perceivably an important innovation to enhance accountability, eliminate fraud, facilitate accurate recording and processing of financial information besides other pros, it has not lived to its expectations considering a number of the shortcomings pointed out. The study also revealed that the relationship between fiscal decentralization and Budget Implementation was strong, positive and statistically significant. The findings of the study indicated that more decentralization of powers, authority and responsibility over the finances to the devolved governments enables the Kenya city counties to correct their fiscal imbalances and appropriate the revenues for effective and efficient project execution as budgeted for. However, the pursuit of further fiscal decentralization should be well calculated and regulated to ensure both the national and county governments remain relevant to the economy.

\subsection{Recommendations}

The recommendations made herein were based on the study findings in relation to the existing literature. According to the findings presented in the previous chapter, the following recommendations were imperative: First, considering that despite IFMIS Re-engineering efforts in two phases following its adoption in Kenya in 2003, this study recommends a complete decentralization of the integrated financial management information system operations and maintenance to county governments to enable the users have additional rights to operate it, but with stronger controls and strict monitoring. As of now, it is recommended that the national treasury should reduce the turn round time for resolution of IFMIS issues and shortcomings whenever they rise and enhance knowledge sharing between IFMIS staff at both levels of government. On the same note, this study 
recommends continuous, effective and thorough training of all IFMIS users at all levels to enhance budget performance. The study also recommends that the government should consider a complete overhaul, or a comprehensive upgrade of the system or introduce a more functional and efficient system that is not prone to system downtimes, failure or complications. The study further recommends more fiscal decentralization to enhance public service and execution of budgeted projects. However, the pursuit of further fiscal decentralization should be well calculated to ensure both the national and county governments remain relevant to the economy. It is also recommended that some counties have been returning unutilized resources to the exchequer. In this regard, the counties should properly utilize the available resources to provide for the public interests and that members of the public be called upon to participate more actively in budget formulation and execution.

\subsection{Areas of Further Studies}

Based on the study findings, it is important that further research be done on IFMIS to come up with a more effective or a complete overhaul for there to be a better system for public financial management. Considering that there are a total of seven areas of public financial management reforms, studies should as well be done to unearth the effectiveness of external audits and e-procurement on budget execution by city counties. Studies should also be done to unearth the interrelation between adoption of PFMR and performance of counties in rural areas in Kenya.

\section{References}

[1] Ahmad, A., \& Ahmad, B. (2014). Obstacles of Preparing and Implementing the Budgets in Jordan. Interdisciplinary Journal of Contemporary Research in Business, 6 (2), 104113.

[2] Aiginger, K., Cramme, O., Ederer, S., Liddle, R., \& Thillaye, R. (2012). Reconciling the Short and Long Run Governance Reforms to Solve the Crisis and Beyond. European Policy Brief, 1-13.

[3] Aminatu, M. (2015). The Impact of Integrated Financial Management System on Economic Development: The Case of Ghana. Korea Review of International Studies, pp. 61-80.

[4] Andrews, M. (2010). How Far Have Public Financial Management Reforms Come in Africa. Harvard Kennedy School Working Paper Series, 1-72.

[5] Bagaka, O. (2008). Fiscal Decentralization in Kenya: The Constituency Development Fund and the Growth of Government. 20th Annual Conference of the Association for Budgeting and Financial Management, October, 23-28, Chicago, pp. 1-40.

[6] Boetti, L., Piacenza, M., \& Turati, G. (2010). Decentralization and Local Governments' Performance: How Does Fiscal Autonomy Affect Spending Efficiency. Department of Economics and Public Finance G. PRATO"Working Paper Series. Alma Universita Tauriensis, 1-37.
[7] Borland, J. (2001). Microeconomic Reforms in Australia-An Introduction. University of Melbourne, 1-11.

[8] Bosire, K. K. (2016). The Impact of Integrated Financial Management Information System on Financial Probity in The Public Sector in Kenya. Research Project, pp. 1-42.

[9] Bovaird, T., \& Loffler, E. (2009). Public Management and Governance. London: Routledge.

[10] Brunson, T. (2017). Public Financial Management Reform. Ministry of Finance and Development Planning, Republic of Liberia, 1-10.

[11] Commission on Revenue Allocation, Kenya. (2016). Total Allocations to County Governments (Equitable and Conditional Transfers).

[12] Dener, C. \& Young, S. (2013). Financial Management Information Systems and Open Budget Data: Do Governments Report on Where the Money Goes? Washington DC: World Bank Publications.

[13] Donaldson, T. \& Preston, L. E. (1995). "The Stakeholder Theory of the Corporation: Concepts, Evidence, and Implications. Academy of Management, 65-91.

[14] Elhiraika, A. B. (2007). Fiscal Decentralization and Public Service Delivery in South Africa. African Trade Policy Center Work in Progress No. 58, 1-25.

[15] Fabozzi, F. J., Gupta, F. \& Markowitz, H. M. (2002). The Legacy of Modern Portfolio Theory. The Journal of Investing, pp. 7-22.

[16] Francesco, B. B. (2013). The Reform of the Public Administration in Singapore: A Model to Follow in Italy. Italia Ministry of Agricultural, Food and Forestry Policies. Munich Personal RePEc Archive, 1-16.

[17] Gachithi, E. W. (2010). The Challenges of Budget Implementation in Public Institutions: A Case Study of University of Nairobi. Unpublished Research Project. University of Nairobi, 168.

[18] Gomes, R. C. (2006). Stakeholder Management in the Local Government Decision-Making Area: Evidences from a Triangulation Study with the English Local Government. Brazilian Administrative Review, vol. 3 (1), pp. 46-63.

[19] Griesse, J., \& Deroose, S. (2014). Implementing Economic Reforms - Are EU Member States responding to European Semester Recommendations? ECFIN Economic Brief, 37 (2014), 1-9.

[20] Guthrie, J., Olson, O., \& Christopher, H. (1999). Debating Developments in New Public Management: The Limits of Global Theorising and Some New Ways Forward. Financial Accountability and Management, 15 (3) \& (4).

[21] Guthrie, J. (2005). International Public Financial Management Reform: Progress, Contradictions, and Challenges. Greenwich Conn: Information Age Publishers.

[22] Hendricks, C. J. (2012). Integrated Financial Management Information Systems: Guidelines for Effective Implementation by the Public Sector of South Africa. $S A$ Journal of Information Management, 14 (1), pp. 529-538.

[23] Khan, A. \& Hildreth, W. B. (2002). Budget Theory in the Public Sector. London: Quorum Books. 
[24] Kiilu, M. R., \& Ngugi, K. (2014). Effect of Public Financial Management Reforms in the Effective Management of Punblic Funds in Kenya: A Case Study of the National Treasury. European Journal of Business Management, 2 (1), 161-169.

[25] Kis-Katos, K., \& Sjahrir, B. S. (2014). The Impact of Fiscal and Political Decentralization on local public investments in Indonesia. University of Freiburg, Department of Interational Economic Policy Discussion Paper Series Nr 25, pp. 1-34.

[26] Lao-Araya, K. (2002). Effect of Decentralization Strategy on Macroeconomic Stability in Thailand. ERD Working Paper Series no. 17. Asian Development Bank, p. 1-31.

[27] Martinez-Vazquez, J., Lago-Penas, S., \& Saachi, A.(2015). The Impact of Fiscal Decentralization: A Survey. Governance and Economic Research Network, pp. 1-32.

[28] Mkasiwa, T. A. (2013). Implementation of Budgetary Reforms in Tanzania: Policy Brief No. 6. Tanzania Country Level Knowledge Network, 1-20.

[29] Mugambi, K. W., \& Theuri, F. S. (2014). The Challenges Encountered By County Governments in Kenya During Budget Preparation. IOSR Journal of Business and Management, 16 (2), pp. 128-134.

[30] National Council for Law Reporting. (2012). Urban Areas and Cities Act. Laws of Kenya, 1-31.

[31] Neyapti, B. (2005). Fiscal Decentralization and Deficits: International Evidence. Ankara, Turkey: Bilkent University.

[32] Njenga, A. N., Omondi, M. M., \& Omete, F. I. (2014). Financial Management Reforms and Economic Performance of Public Sector in Kenya. International Journal of Business and Management, 6 (31), 148-161.

[33] Njeru, P. N. (2016). An Assessment of Integrated Fiancial Management Information System Implementation towards Effective Management Practices in Nairobi and Lamu Counties. Strathmore University Electronic Theses and Dissertations, 1-64.

[34] Omisore, I., Yusuf, M., \& Nwufo, C. I. (2012). The Modern Portfolio Theory as an Investment Decision Tool. Journal of Accounting and Taxation, vol. 4 (2), p. 19-28.

[35] Onduso, E. A. (2013). The Effect of Budgets on Financial Performance of Manufacturing Companies in Nairobi County. Unpublished thesis. University of Nairobi, 1-93.

[36] Onyiah, A. I., Ezeamama, N. N., Ugwu, J. N. \& Mgbodile, C. C. (2016). Nigerian Budget Implemetation and Control Reforms: Tool for Macro Economic Growth. British Journal of Economics, Management \& Trade, 11 (2), 1-13.
[37] Parham, D. (2002). Microeconomic Reforms and the Revival in Australia's Growth in Productivity and Living standards. Conference of Economists, (pp. 1-29). Adelaide.

[38] Rajasekar, S., Philominathan, P., \& Chinnathambi, V. (2013). Research Methodology. Bharathidasan University. India.

[39] Ross, S., Westerfield, R. \& Jaffe, J. (2009). Corporate Finance, 5th edition, Irwin and McGraw Hill, Boston.

[40] Samadi,. H., Keshtkaran, A., Kavosi, Z., \& Vahnedi, S. (2013). The Effect of Fiscal Decentralization on Under-Five Mortality in Iran: A Panel Data Analysis. International Journal of Health Policy and Management, 1 (4), 301-306.

[41] Scheers, B., Sterck, M., \& Bouckaert, G. (2005). Lessons from Australian and British Reforms in Results-Oriented Financial Management. OECD Journal of Budgeting, 5 (2), 133-162.

[42] Schwarz, G. (2013). Response Rate in European Business Tendency Surveys. Australian Institute of Economic Research, $1-54$.

[43] Wakhungu, D. (2014). Impact of Public Finance Management Reforms on Financial Performance of Commercial State Owned Enterprises in Kenya. Unpublished Research Project. University of Nairobi, 1-60.

[44] Golafshani, N. (2003). Understanding Reliability and Validity in Qualitative Research. The Qualitative Report, 8 (4).

[45] Kombo, K. \&. Tromp, C. (2006). Proposal and Thesis Writing. Makuyu: Pauline Publications.

[46] Kothari, C. R. (2004). Research Methodology: Methods and Techniques (2nd Ed.. New Delhi: New Age International (P) Limited.

[47] Robson, C. (2002). Real World Research. A Resource for Social Scientists and Practitioner Researchers, 2nd edition. Blackwell: Oxford.

[48] Sapsford, R., \& Jupp, V. (2006). Data Collection and Analysis. London. Sage Publications.

[49] Saunders, M., Lewis, P., \& Thornhill, A. (2009). Research Methods for Business Students. England: Pearson Education Inc.

[50] Welman, C., Kruger, S. J. \& Kruger, F. (2001). Research Methodology for Business and Administrative Sciences. United Kingdom. Oxford University Press. 